\title{
Serious Games in an Information Technology Course: Opportunities, Challenges, and Outcomes
}

\author{
Amir Hossein Ghapanchi \\ School of Information and Communication Technology, Griffith University \\ Gold Coast, Queensland, 4222, Australia \\ E-mail: a.ghapanchi@griffith.edu.au \\ Alireza Amrollahi \\ School of Information and Communication Technology, Griffith University \\ Gold Coast, Queensland, 4222, Australia \\ E-mail: alireza.amrollahi@griffithuni.edu.au
}

\begin{abstract}
Serious games (SG) and Game-Based Learning (GBL) have frequently used for teaching purpose in different courses including Information Technology (IT). However, qualitative studies of students' experience in using this approach have been subject of less attention in the related literature. The current study employs a qualitative approach to gain insight on students' opinion after using the SGs in an IT course. The study particularly pays attention to potential opportunities and challenges of using the approach in IT course. Moreover, we asked students' about the possible skills which they learnt through use of SGs. Fifty four students participated in a written survey which contained three open-ended questions about students' experience in using this approach. After analysis of the results three groups of opportunities (learning outcome, engagement, and real life opportunity), three groups of challenges (learning curve, capacity of learn, and design of the game), and six groups of possible skills (human resource management, resource management, leadership, management and business skills, strategic skills, and technical knowledge) are recognised according to students' experience. This study concludes with some implications for practice and research.
\end{abstract}

Keywords: Serious games, Information Technology, Game Based Learning, Opportunity, Challenge.

\section{Introduction}

The games-based learning (GBL) concept has been introduced as a new tool for education in 1990s and consequently "Serious Game” (SG) or "applied game” as a type of games which are used in this approach. However, games have been used as a tool for education since $1900 \mathrm{~s}$ and paper-based games were very interesting in 1960s and 1970s ${ }^{1}$. These games are designed to improve specific aspects of learning and teaching by simulating the real process and provide the learners with the ability to experience situations that are not easy to deal with in the real environment ${ }^{2}$.
The SGs market currently worth \$20 million while the revenue of worldwide computer and video games industry is estimated to be $\$ 10$ billion in $2005^{3}$ and more than $\$ 25$ billion in $2010^{4}$. Serious games also have the opportunity to constitute a remarkable part of the global education and training market, which was estimated to be worth $\$ 2$ trillion in $2003^{5}$.

GBL approach and SGs have already been applied to a variety of topics in education Prensky ${ }^{6}$ mentioned three levels for application of GSs: learn to do things (flying airplanes), learn infinitely more (take in information and make decisions), and learn to collaborate. The motivating and engaging features of games, teamwork experiences, decision making and suggestions that 
players might develop in the game procedure are features that have made the SGs considered as efficient and attractive, new methods of learning-by-doing. For this reason they have been applied to a broad spectrum of application like healthcare, emergency management, education, city planning, engineering and so forth.

In the late 1990s and especially after 2000, SGs entered Information Technology (IT) subjects. This includes topics such as: computer Integrated Manufacturing (CIM) ${ }^{7}$, information systems development ${ }^{8}$, and Decision Support Systems (DSS) ${ }^{9}{ }^{10}$. These games were designed in a way which engaged the students with real life challenges in each area and then asked them for the best solution for these problems. However, few studies could be found which provide a comprehensive study on the effectiveness of SG in IT courses.

The current study aims at assessing the effectiveness of SGs in IT courses. The current study reports a case study of using serious games in an IT course for business students. By adopting a qualitative approach, the article aims to answer the following research questions:

RQ1. Which opportunities are perceived by IT course students in the use of serious games?

RQ2. Which challenges are perceived by IT course students in the use of serious games?

RQ3. Which skills could be achieved through use of serious games in the IT course students according to students' experience?

The remainder of this paper is organised as follows: section 2 depicts research background on use of serious games in IT course. Section 3 describes our method for conducting the research and the results of our study are explained in section 4 and finally section 5 contains concluding points as well as research implications for both research and practice.

\section{Research background}

As mentioned before, serious games have been used in IT courses since 1997. In the first article we found on the topic two games (PMSG and BPSG) were developed for CIM subject ${ }^{7}$. The life cycle of a generic one-of-akind delivery project is fully simulated in one of these games with a few duration sample dates of the project. The other one simulated the main business process chains of the whole company.

The other game in this area is "THE MIS" which is developed for information systems development course.
The game is designed around the project management and traditional information systems development approaches ${ }^{8}$. The Chief Knowledge Officer (CKO) game is also developed for Knowledge Management concept in which participants face challenges of knowledge management and learn how their decisions could affect the outcome of the company. Players are grouped into knowledge management teams to assist the Chief Knowledge Officer of a company to go through eight business cycles of decision making ${ }^{11}$.

Other areas of IT/IS in which SGs have been used are Decision Support System (DSS) with "NITOPIA" game 9 and "SDSim" Connolly, Stansfield ${ }^{10}$, computational thinking and learning traditional programming ${ }^{12}$, computer programming (CP) with "Prog\&Play" game

${ }^{13}$. Role playing games are another category of games which have been used for IT courses. The game "Second life (SL)" is one of them which are developed to enhance the ability of learning decision-making topics. It is a virtual world environment which simulates a telecommunication lab with all contents and avatars are assigned to the students to play different role and interact with others to do their tasks ${ }^{14}$.

Plenty of research has been undertaken in 2012 which show that the SGs have become the centre of attention recently. For instance, E. Nunohiro et al. ${ }^{15}$ reported the design, implementation, and assessment of the Gamethemed programming assignment (GTA) modules for computer programming courses. Each assignment module is designed to be self-contained and include materials for the students. There are seven assignment examples which each one consist of a role-playing game to improve the introductory programming concepts. N. Adamo-Villani et al. ${ }^{16}$ nominated the development and initial evaluation of a serious game that can be used to teach secure coding and Information Assurance (IA) concepts in computing courses. The game consists of seven levels which each one is an engaging IA room with a specific IA concept. By selecting different levels the students are introduced to the concepts by the room robot through narration, text, and images. C. Caulfieldet al. 17 designed "Simsoft" which is a bored-game regarding project management education. The game was on the board and the players gather around it to discuss the current state of their project and to consider their next move. There is also a simple Java-based dashboard to show the players the current and historical state of the project through reports and messages. 
Purarjomaldlangrudi and Ghapanchi ${ }^{2}$, listed 18 games which are cited in scientific research papers and categorised them in five groups of simulation games, puzzle-solving games, board games, 3D games, and role playing games. Their review also indicated that the majority (62\%) researches on use of SG in IT courses have applied surveys and questionnaires and 33\% conducted the observation while only $5 \%$ interviewed the participants.

\section{Research Method}

The current study employs qualitative approach to understand students' experience after using SG in an IT course. We used the IT manager: Duels ${ }^{18}$ game in which players are asked to play the role of a real IT manager and use their skills in managing resources (such as: software, hardware, network, and human resources) and increase the functionality of their firm while they are taking care of possible challenges and risks (such as: malwares, network damages, providers' contract).

The course which was selected for running this game was Business Informatics in which (mostly first-year) students of business school, learn basics about use of IS and IT in managing the organisation. There is an emphasis on principles, applications and ethical considerations of electronically mediated business. The course examines information systems and computer concepts relevant to the post millennial structures of interactive technologies, decision-making, strategic thinking, and web applications. Skills in the use of software packages and web applications are also developed.

\subsection{Data collection}

Students were asked to first register and try the game in a supervised computer lab. This first try was beneficial for students while they had the opportunity to ask questions about both the game and concepts which are used in the game from their tutors. Then in the next week, students were asked to play the game again in an online session and explain their experience about the game. Four weeks later students were asked to voluntarily and anonymously participate in a survey and provide their opinion about the used approach.

This survey contains three qualitative open-ended questions which aimed at understanding the students' opinion about the three above mentioned questions. Although written qualitative survey is mentioned less efficient in many aspects, but many advantages have also been cited for them. They can help to discover unanticipated findings and permit creativity, selfexpression, and richness of detail ${ }^{19,20}$. In current study this method also helped us to maximise the participants in the research to 54 (response rate of \%26). While part of the research team was also part of the teaching team, this approach helped us to face the ethical consideration about unequal relationship between research team and participants.

\subsection{Analysis}

The text analysis approach which is suggested by Ezzy 21, 22 was used for the current study. This method is

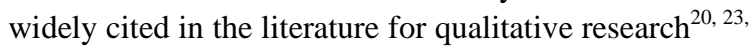

24 . First all the answers were divided to specific quotes and then we analysed those quotes in three categories of opportunities, challenges and skills and labelled them with appropriate code. In this round we found 167 quotes and 37 different codes. After that we reviewed the codes and combined some of them to arrive at a final set of 12 groups of codes which are presented in the result section. 
Table 1. Codes in qualitative analysis

\begin{tabular}{|c|c|c|c|c|}
\hline \multirow[t]{2}{*}{ Category } & \multicolumn{2}{|c|}{ First round of coding } & \multicolumn{2}{|c|}{ Second round of coding } \\
\hline & Code & Frequency & Code & Frequency \\
\hline \multirow{9}{*}{ Challenge } & Difficulty & 16 & Learning curve & 16 \\
\hline & Lack of learning & 5 & \multirow{4}{*}{ Capacity for learn } & \multirow{4}{*}{8} \\
\hline & Doesn't add much for future career & 1 & & \\
\hline & Not suitable for university & 1 & & \\
\hline & Cannot teach everything & 1 & & \\
\hline & Poor instruction & 1 & \multirow{3}{*}{ Design of the game } & \multirow{4}{*}{3} \\
\hline & Based on Chance & 1 & & \\
\hline & Long & 1 & & \\
\hline & Fun & 17 & \multirow{4}{*}{ Learning Outcome } & \\
\hline \multirow{8}{*}{ Opportunity } & Learn & 19 & & \multirow{3}{*}{47} \\
\hline & Interactive & 3 & & \\
\hline & Easy & 8 & & \\
\hline & Motivation & 1 & \multirow{3}{*}{ Engagement } & \multirow{3}{*}{4} \\
\hline & Engaging & 2 & & \\
\hline & Involving & 1 & & \\
\hline & Real life & 8 & \multirow{2}{*}{ Real life opportunity } & \multirow{2}{*}{9} \\
\hline & Use of knowledge & 1 & & \\
\hline \multirow{15}{*}{ Skills } & Human Resource Management & 13 & \multirow{2}{*}{\multicolumn{2}{|c|}{ Human Resource Management15 }} \\
\hline & Team development & 2 & & \\
\hline & Project management & 8 & \multirow{3}{*}{$\begin{array}{l}\text { Management and business } \\
\text { skills }\end{array}$} & \multirow{3}{*}{19} \\
\hline & Decision making & 4 & & \\
\hline & Business environment analysis & 7 & & \\
\hline & Flexibility & 2 & \multirow{5}{*}{ Leadership } & \multirow{5}{*}{9} \\
\hline & Multi-tasking & 1 & & \\
\hline & Leadership & 3 & & \\
\hline & Communication & 1 & & \\
\hline & Problem solving & 2 & & \\
\hline & Time management & 5 & \multirow{2}{*}{ Resource management } & \multirow{2}{*}{15} \\
\hline & Resource management & 10 & & \\
\hline & Strategic planning & 15 & Strategic skills & 15 \\
\hline & Technical knowledge & 3 & \multirow{2}{*}{ Technical knowledge } & \multirow{2}{*}{8} \\
\hline & Security management & 5 & & \\
\hline
\end{tabular}

\section{Results}

As mentioned above, we categorised the codes in three categories of opportunities, challenges, and skills. The result of our qualitative analysis is described below:

\subsection{Opportunities}

Our analysis of the students' experience in working with the software revealed many opportunities which are mentioned by students in use of the SGs in IT courses. We categorised these opportunities in three groups of "learning outcomes, engagement, and real life opportunity”.

\subsubsection{Learning outcome}

The main purpose of using the approach is to facilitate the learning and teaching process. This goal has been fulfilled according to most of the interviews in our study. Students have expressed that this method has made an opportunity for them to learn easily and in a fun or enjoying way.

One of them for example mentioned: "This is a fun way to learn some important concepts around IT Management. You learn without even trying." They have also compared it to habitual methods of learning, teaching and evaluation. For example one of them compared that with open book quizzes: "I disliked how the online quizzes were simple fill in the blank 
questions and was basically just a test for who could find the answer from the text the quickest instead of testing our knowledge of MIS.” Others have compared the interactive way of learning in serious games with traditional learning system: "IT Manager was beneficial because it was a visual and interactive way of learning. The results of this type of learning personally are higher than reading out of a textbook."

\subsubsection{Engagement}

We find several quotes in our survey in which students mentioned increase their engagement with the course. This could be related to the nature of games which entails competitions with others or the compute: "By playing against the computer this game created a motivational and persistent drive within myself to achieve high scores and focus more intently on how I was playing the game."

Another student mention a great opportunity for students to learn from their mistakes: “Overall, a useful and engaging game that plays on a student's competitive nature and eagerness to learn (especially from mistakes), with an accurate business setting.”

\subsubsection{Real life opportunity}

We finally understood that according to the survey, the game has provided the opportunity to many students to experience the problems which IT professionals encounter during their daily activities: "The IT manager's game allows students to analyse systems, create, maintain and provide protection for their systems in the virtual IT world which students can apply to the real world."

This opportunity is more highlighted for the students when they can use their knowledge form course in resolving the real life problems of IT profession: "During my time playing the IT manager game, I found that it challenged my basic IT fundamental knowledge which I had to apply in order to win.” This experience is especially valuable for business students and they can better understand that "management of IT companies does not always go as smoothly as expected and the uncontrollable nature of IT systems ensures that it is rarely smooth sailing when it comes to day to day activities.”

\subsection{Challenges}

The result of analysing the qualitative text also revealed some challenges in implementing the SG tools in IT courses. We categorise these challenges in three groups of "learning curve, learning capacity, and the design of the game" which are explained in detailed below:

\subsubsection{Learning curve}

Although many students mentioned SG as an easy way of learning (see section 4.1.1), many others have highlighted this as a challenge that it has taken a lot of time for them to learn how to play the game: "The first time I played, it didn't give me anything I could play.”

This could be justified with the "learning curve" concept which indicates improvement patterns in learning abilities over time ${ }^{25,26}$. In the current study also students have also mentioned that in future tries, they witnessed improvements in learning the game: "Learning how to play the game was the most confusing aspect of IT Manager, however, once I learnt how to play and how to win it was relatively easy from there.”

\subsubsection{Capacity of learn}

In contradiction with the quotes which are mentioned in section 4.1.1, we found several quotes from students which questioned the potential of learning with SGs: "Overall the game was quite interesting and it did help me enhance my knowledge as to how some programs work and what to look out for. However in regards to where I want to end up in my future career, this did not really benefit me. Will recommend this game to students willing to do further studies in this area.”

One of the reasons which have been mentioned for this is the difficulty of understanding the game especially in the initial tries (see section 4.2.1): "I found it really hard to figure out how to play and it still confuses me. I don't really know what's going on. [I] didn't really learn anything." Moreover, some of the students have questioned the suitability of using "games" in the universities: "I think that type of interactive learning via that type of game is more suited towards primary or junior high school students' not twenty year old university students who take time out of their days to be present on campus." And mentioned that they "prefer an actual teaching of how each of the components interacts in daily life over a game.” 


\subsubsection{Design of the game}

The last category of challenges of SGs which is mentioned in the quotes of our qualitative study is related to the used game. First of all students have mentioned that the game "was a little bit long, by the end I was bored." Moreover, some of them mention "poor instruction" as a shortcoming in the game which has ended in confusion in first tries. Finally another student mentioned "the fact that [the game] was based on chance" as a factor which prevent efficient learning with this game. Fig. 1 depicts the opportunities and challenges of using SGs in IT courses.

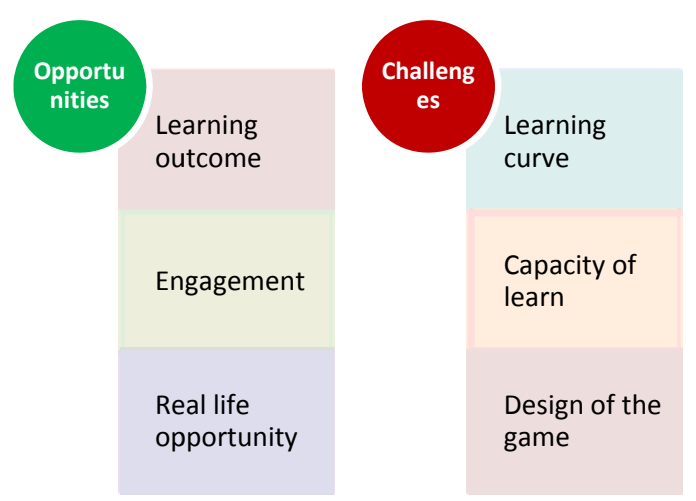

Fig. 1. Opportunities and challenges of using SGs in IT courses

\subsection{Skills}

We also asked students for the possible skills which they can learn through use of serious games. Surprisingly they mentioned a variety of skills which they have learnt or practiced by using serious games. We categorised these skills in six groups:

\subsubsection{Human resource management}

Managing the IT staff with various skills is one of the potential skills which is possible to be acquired according to our qualitative data: "The game teaches many lessons including how to assign staff effectively making sure they are being used to their maximum potential when they are available.” The ability of an IT manager to develop and manage a team with diverse skills as well as monitoring their performance has also been highlighted in the students' quotes.

\subsubsection{Resource management}

More than human resources, effective management of technology resources is another aspect of IT managers' skills which could be learnt through the game: "I learnt that in order to be an IT manager, a delicate balance between software, hardware and resources is crucial in order to satisfy business needs.” They have also found time as an important resource which should carefully managed by the IT manager: "In my experience with the IT manager game [time management] was an important characteristic because there were limiting time constraints on each round and the time required for staff to perform the assigned tasks varied.”

\subsubsection{Leadership}

Different aspects of leadership skills are also reflected as parts of the quotes in our study. For example one student mentioned multi-tasking as an important skill which is highlighted in playing with the game: "A successful IT manager should have enough experience to be able to undertake more than one task/project at a time, using delegation and collaboration where possible. This leads to increased productivity and prosperity."

They have also mentioned capabilities like communication (with employees of all levels), problem solving, flexibility ("to changing technology, as well as situations that may arise that need immediate action”), and team development as parts of this category.

\subsubsection{Management and business skills}

A variety of general management and business skills are also mentioned in our study which students have acquired while playing the serious game. Decision making is one of these capabilities: "An IT manager must be competent in making decisions at all levels, which could be anything from deciding which team members to allocate to a task, through to which system and technology is most appropriate for a project.”

An operating knowledge of the business in which the firm works and ability to analyse the environment and competitors is also highlighted in the game according to our study. This can be learnt through monitoring the activities of your competitors (human or computer) and the harms they may cause in your systems. Finally we find project management as an important skill in this 
category: "Throughout the game I had to continually manage my projects accordingly, just like a real IT manager would face on a daily basis.”

\subsubsection{Strategic skills}

More than operational skills which stated above as required skills for IT managers, our study indicated many quotes which mentioned long-term and strategic skills to be required for IT managers. In some quotes the ability to forecast the future challenges has been highlighted: "I learnt that strategy and foresight regarding system expansion, updating technology, possible problems and solutions, and maintenance of equipment and repairs, are vital components in effectively running an information system.”

Some other students, however, have mentioned the strategic planning ability as a required skill: "I learnt that strategic and tactical planning was needed to ensure that the resources were managed effectively. For example, it was important to balance the allocation of equipment with the number of staff that needed to be allocated.”

\subsubsection{Technical knowledge}

Finally technical knowledge of IT is stated in our study as a required skill for IT managers: "Manager needs to be aware of, and able to manage, threats such as viruses, email worms, overheating, viral videos, DDOS attacks, flood and unmanaged expansion. Thus, it is crucial that an IT Manager can adapt in this volatile environment and adequately allocate staff to necessary tasks.” Fig. 1 depicts the opportunities and challenges of using SGs in IT courses. Fig. 2 shows the potential skills which could be acquired by using SGs in IT course.

\section{Discussion}

This study applies a qualitative approach to study opportunities and challenges in using serious games for teaching purposes in IT courses. Moreover we studied student's experience about the skills which they believe they could learn by using the SG in business informatics course. Our background study of the literature ${ }^{2}$ indicated that the quantitative and surveys and observations have been the most relevant approaches in evaluating use of SG in IT courses and to best of our knowledge, this qualitative study of students' experience is performed for the first time in the current study and can result in several implications for practitioners and research.

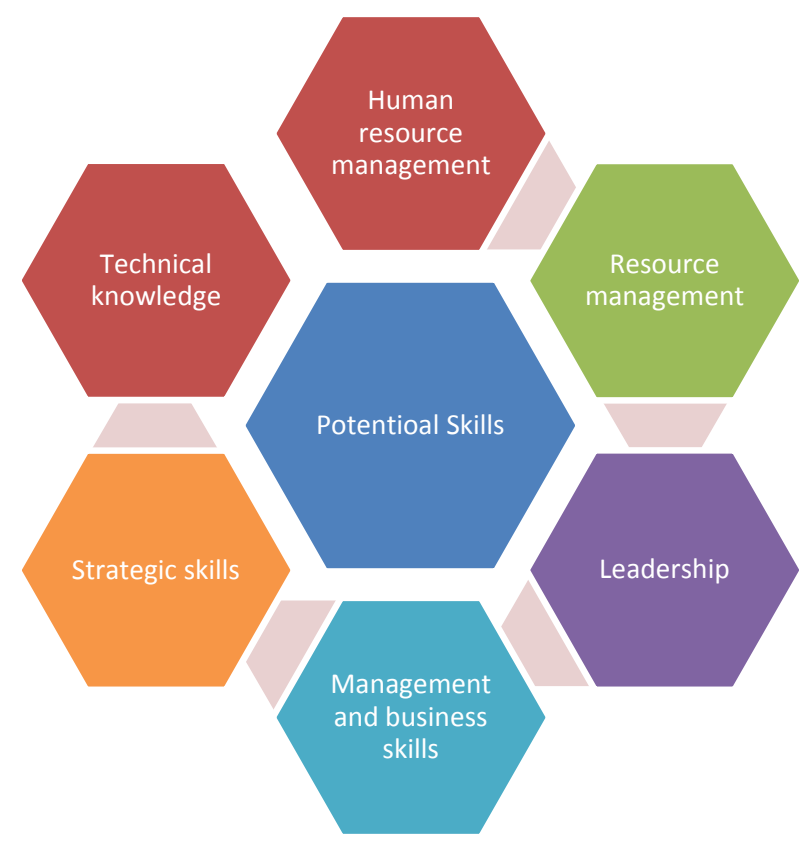

Fig. 2. Potential skills which could be acquired by using SGs

The current study provides an insight to challenges and opportunities which students may encounter when learn through GS in IT courses. This may help IT schools and instructors in IT courses to better understand the opportunities of SG in the course and better plan for use of this approach in various IT related courses. As stated in section 4.1, this approach can improve the learning outcomes and students' engagement in the IT course (are challenges of in many courses) by providing a new enjoyable medium of learning which. Moreover it helps the course to simulate the challenges in management of IT in real firms. For this reason, it can be best applied to courses like "business informatics" and "Management Information Systems (MIS)” in which students should go further than use of technology and learn different social aspects of using IT and IS in an organisation.

Course conveners who have already selected the SG approach to deliver all or part of their course should also be aware of the possible challenges which students have faced for learning with SG and try to avoid them in their practices. The main recognised challenge is the learning curve of such games which may hinder the start of effective learning. In order to avoid this challenge, 
practitioners should provide complete and clear instructions for students and provide more supervised sessions for playing SGs.

Developers of serious games should also pay attention to these challenges and shortcomings in order enhance the capability of learning for their games. In particular, better instructions for the games and improved design for the game can increase the learning outcomes of the game.

Finally our study of the students' opinion about the skills which they can learn through playing SGs can be used by practitioners as a guideline for development of courses. These findings are consistent with the literature on skills and capabilities of IT managers ${ }^{27-30}$ and contain a diverse range of skills.

\section{References}

1. Rice, J., Assessing Higher Order Thinking in Video Games. Journal of Technology and Teacher Education, 2007. 15(1): p. 87-100.

2. Purarjomaldlangrudi, A. and A.H. Ghapanchi, Applications of Educational Serious Games for Information Technology Related Subjects in Higher Education. The International Technology Management Review, 2013. 3(3): p. 196-207.

3. Van Eck, R., Digital game-based learning: It's not just the digital natives who are restless. EDUCAUSE review, 2006. 41(2): p. 16.

4. Gallagher, M.D., Entertainment Software Association 2010 ANNUAL REPORT, 2010, Entertainment Software Association.

5. David, M. and C. Sande, Serious Games: Games That Educate, Train, and Inform. Boston: Thomson Course Technology, 2006.

6. $\quad$ Prensky, M., Digital game-based learning. Computers in Entertainment (CIE), 2003. 1(1): p. 21-21.

7. Savolainen, T., Simulation games in CIM and the learning organisation. Computers in industry, 1997. 33(2): p. 217-221.

8. Martin, A., The design and evolution of a simulation/game for teaching information systems development. Simulation \& Gaming, 2000. 31(4): p. 445-463.

9. Ben-Zvi, T., Using business games in teaching DSS. Journal of Information Systems Education, 2007. 18(1): p. 113-124.

10. Connolly, T.M., M. Stansfield, and T. Hainey, An application of games-based learning within software engineering. British Journal of Educational Technology, 2007. 38(3): p. 416-428.

11. Chua, A.Y., The design and implementation of a simulation game for teaching knowledge management. Journal of the American Society for Information Science and Technology, 2005. 56(11): p. 1207-1216.
12. Kazimoglu, C., et al. Developing a game model for computational thinking and learning traditional programming through game-play. in World Conference on E-Learning in Corporate, Government, Healthcare, and Higher Education. 2010.

13. Muratet, M., et al. Experimental feedback on Prog\&Play: a serious game for programming practice. in Computer Graphics Forum. 2011. Wiley Online Library.

14. Goel, L., et al., Decision-making in-socio and insitu: Facilitation in virtual worlds. Decision Support Systems, 2012. 52(2): p. 342-352.

15. Nunohiro, E., et al., Development of game-based learning features in programming learning support system. Artificial Life and Robotics, 2012. 17(3-4): p. 373-377.

16. Adamo-Villani, N., M. Oania, and S. Cooper, Using a Serious Game Approach to Teach Secure Coding in Introductory Programming: Development and Initial Findings. Journal of Educational Technology Systems, 2012. 41(2): p. 107-131.

17. Craig Caulfield, S.P.M., Jianhong (Cecilia) Xia, D Veal, Shall We Play a Game? Modern Applied Science, 2012. Vol. 6, No. 1.

18. Intel, it manager: duels, 2012.

19. Neuman, L.W., Social Research Methods, 7/E2011: Pearson Education India.

20. Ghapanchi, A.H., et al., A methodology for selecting portfolios of projects with interactions and under uncertainty. International Journal of Project Management, 2012. 30(7): p. 791-803.

21. Ezzy, D., Qualitative Analysis: Practice and Innovation2002: ROUTLEDGE CHAPMAN \& HALL.

22. Ghapanchi, A.H. and A. Aurum. Measuring the effectiveness of the defect-fixing process in open source software projects. in System Sciences (HICSS), 2011 44th Hawaii International Conference on. 2011. IEEE.

23. Najaftorkaman, M., et al., A taxonomy of antecedents to user adoption of health information systems: A synthesis of thirty years of research. Journal of the Association for Information Science and Technology, 2014.

24. Amrollahi, A., A.H. Ghapanchi, and A. TalaeiKhoei, A Systematic Literature Review on Strategic Information Systems Planning: Insights from the Past Decade. Pacific Asia Journal of the Association for Information Systems, 2013. 5(2): p. 39-66.

25. Yelle, L.E., The learning curve: Historical review and comprehensive survey. Decision Sciences, 1979. 10(2): p. 302-328.

26. Spence, A.M., The learning curve and competition. The Bell Journal of Economics, 1981: p. 49-70.

27. Lee, S.M. and C.K. Lee, IT managers' requisite skills. Communications of the ACM, 2006. 49(4): p. 111-114.

28. Haggerty, N. Understanding the link between IT project manager skills and project success research in progress. in Proceedings of the 2000 ACM 
SIGCPR conference on Computer personnel

research. 2000. ACM.

29. Gramignoli, S., A. Ravarini, and M. Tagliavini. A

profile for the IT manager within SMEs. in

Proceedings of the 1999 ACM SIGCPR conference on Computer personnel research. 1999. ACM.

30. Ghapanchi, A.H. and A. Aurum, The impact of project capabilities on project performance: case of open source software projects. International Journal of Project Management, 2012. 30(4): p. 407-417.

Published by Atlantis Press

Copyright: the authors 